\title{
Analisa Uji Kekerasan dan Uji Tarik Material AISI P20 Mod. Hasil Perlakukan Hardening dan Tempering
}

\author{
Roni Kusnowo \\ Politeknik Manufaktur Negeri Bandung \\ Jl.Kanayakan no.21 Dago, Bandung, 40135 \\ E-mail : roni@polman-bandung.ac.id
}

\begin{abstract}
Abstrak
Penelitian ini bertujuan untuk menganalisis uji kekerasan dan uji tarik pada material AISI P20 Mod. setelah melalui proses hardening dan tempering pada suhu yang berbeda-beda. Hardening adalah proses perlakuan panas yang diterapkan untuk menghasilkan benda kerja yang keras. Proses tempering bertujuan untuk memperoleh kombinasi antara kekuatan, keuletan dan ketangguhan yang tinggi. Material AISI P20 Mod. sebagai material substitusi impor yang diproduksi melalui proses continuous casting dimana dalam proses pembuatannya memerlukan proses rol (rolling) dan proses tempa (forging). Material ini mempunyai sifat dan karakteristik khusus, diantaranya tahan terhadap temperatur tinggi, tahan terhadap abrasi, dan mempunyai mampu mesin yang baik. Hasil penelitian menunjukkan uji kekerasan pada proses hardening mencapai nilai kekerasan 53,7 HRC. Selanjutnya dilakukan proses tempering pada suhu $200^{\circ} \mathrm{C}$ hasil menunjukkan nilai kekerasan sedikit meningkat menjadi $54 \mathrm{HRC}$, sedangkan pada temperatur $400^{\circ} \mathrm{C}$ terjadi penurunan nilai kekerasan menjadi 47,4 HRC. Baru setelah dilakukan tempering pada suhu $600^{\circ} \mathrm{C}$ hasil uji kekerasan menunjukkan masuk target kekerasan yang diinginkan yaitu pada 34 HRC. Hasil uji tarik menunjukkan pada kondisi awal benda, hasil uji tarik adalah $655 \mathrm{~N} / \mathrm{mm}^{2}$. Kekuatan tarik hasil proses hardening sebesar $1244 \mathrm{~N} / \mathrm{mm}^{2}$. Setelah dilakukan proses tempering $200^{\circ} \mathrm{C}$ dihasilkan kekuatan tarik $1515.8 \mathrm{~N} / \mathrm{mm}^{2}$. Pada proses tempering $400^{\circ} \mathrm{C}$, terjadi penurunan nilai kekuatan tarik menjadi $1397.9 \mathrm{~N} / \mathrm{mm}^{2}$. Selanjutnya pada proses tempering $600^{\circ} \mathrm{C}$ nilai kekuatan tarik menjadi $1077.7 \mathrm{~N} / \mathrm{mm}^{2}$, mendekati target kekuatan tarik yaitu $1020 \mathrm{~N} / \mathrm{mm}^{2}$.
\end{abstract}

Kata Kunci: uji kekerasan, uji tarik, hardening, tempering, material AISI P20 Mod.

\section{PENDAHULUAN}

Kebutuhan akan material yang sesuai dengan kebutuhan di dalam industri manufaktur sangat beragam, namun sayang ketersediaan material yang dibutuhkan seringkali sangat sulit didapatkan karena masih banyak material yang diperlukan tidak diproduksi di dalam negeri sehingga harus impor. Hal ini tentu saja cukup menyulitkan dan menambah biaya dan waktu yang dibutuhkan untuk produksi. Oleh karena itu upaya untuk menemukan material substitusi impor sangat dibutuhkan sehingga dapat menghemat waktu dan biaya produksi.

Material AISI P20 Mod. merupakan material substitusi impor yang digunakan untuk kebutuhan material cetakan plastik. Saat ini, cetakan plastik (plastic mold) dalam pembuatannya memerlukan material standar dengan ukuran tertentu dan merupakan produk import dengan tipe AISI P20 Mod., material ini mempunyai keterbatasan, dimana waktu tunggu pemesanan cukup lama. Selain itu, dalam pembuatan komponen cetakan (mold), umumnya menggunakan material berbentuk batang atau balok (bloom), dibentuk dengan proses permesinan dari awal sampai akhir, sehingga banyak material yang terbuang dan memerlukan waktu yang cukup lama.

Komponen plastik sangat dominan dalam industri manufaktur khususnya otomotif, dalam pembuatannya diperlukan cetakan yang terbuat dari material AISI P20 Mod. untuk proses injeksi plastik (plastic injection). Material AISI P20 Mod. diproduksi melalui proses continuous casting yang dalam proses pembuatannya memerlukan proses rol (rolling) dan proses tempa (forging). Material ini mempunyai sifat dan karakteristik khusus, diantaranya tahan terhadap temperatur tinggi, tahan terhadap abrasi, dan mempunyai mampu mesin yang baik.

Untuk mengurangi kerugian material dan mempersingkat waktu permesinan cetakan (mold), maka dilakukan pembuatan cetakan yang mendekati bentuk akhirnya (near shape product) melalui proses pengecoran, dan selanjutnya dilakukan proses permesinan menggunakan CNC untuk mencapai akurasi dimensi. Untuk mendapatkan sifat mekanis material cor AISI P20 Mod. perlu dilakukan proses perlakuan panas, diantaranya hardening dan tempering. 
Hardening adalah proses perlakuan panas yang diterapkan untuk menghasilkan benda kerja yang keras. Perlakuan ini terdiri dari memanaskan baja sampai ke temperatur pengerasannya (temperatur austenisasi), dan menahannya pada temperatur tersebut untuk jangka waktu tertentu dan kemudian didinginkan dengan laju pendinginan yang sangat tinggi atau di quench agar diperoleh kekerasan yang diinginkan (Suratman, 1998:41).

Sedangkan tempering merupakan proses memanaskan kembali baja yang sudah dikeraskan dengan tujuan untuk memperoleh kombinasi antara kekuatan, keuletan dan ketangguhan yang tinggi. Proses tempering terdiri dari pemanasan baja sampai dengan temperatur dibawah temperatur A1, dan menahannya pada temperatur tersebut untuk jangka waktu tertentu dan kemudian didinginkan di udara (Suratman, 1998:77).

Dalam mendapatkan material yang sesuai dengan kebutuhan, maka material substitusi impor yang dalam penelitian ini adalah material AISI P20 Mod., diperlukan suatu uji kekerasan dan uji tarik sebagai salah satu uji yang dilakukan untuk melihat sifat mekanik pada material sehingga dapat disesuaikan dengan kebutuhan industri. Uji kekerasan dan uji tarik dilakukan setelah material baja AISI P20 Mod. mendapatkan perlakukan hardening dan tempering untuk mendapatkan nilai kekerasan dan kekuatan tarik yang diinginkan dari material tersebut.

Berdasarkan uraian di atas maka penelitian ini bertujuan untuk menganalisis uji kekerasan dan uji tarik pada material baja cor AISI P20 Mod. setelah melalui proses hardening dan tempering pada suhu yang berbedabeda, yaitu $200^{\circ} \mathrm{C}, 400^{\circ} \mathrm{C}$ dan $600^{\circ} \mathrm{C}$ dalam upaya mendapatkan material yang sesuai dengan standar yang ditetapkan.

\section{METODE}

Rancangan penelitian dimulai dengan pembuatan material untuk penelitian ini dengan proses pengecoran logam. Pengecoran material AISI P20 Mod. menggunakan kaidah-kaidah pengecoran logam, dimulai dari pembuatan pattern Y-block, pembuatan cetakan, dan peleburan.

Selama proses peleburan dihasilkan material yang sama seperti material target, dengan komposisi sebagai berikut :

Tabel 2.1 komposisi standar material AISI P20 Mod. $(\% \text { berat })^{[1]}$

\begin{tabular}{|c|c|c|c|c|c|c|c|}
\hline $\mathrm{C}$ & $\mathrm{Si}$ & $\mathrm{Mn}$ & $\mathrm{Cr}$ & $\mathrm{Ni}$ & $\mathrm{Mo}$ & $\mathrm{S}$ & $\mathrm{P}$ \\
\hline $0.35-$ & $0.2-$ & $1.3-$ & $1.8-$ & $0.9-$ & $0.15-$ & $<0,010$ & $<0,010$ \\
0.45 & 0.4 & 1,6 & 2.1 & 1,0 & 0,3 & & \\
\hline
\end{tabular}

Sedangkan komposisi peleburan sebagai berikut :
Tabel 2.2 komposisi peleburan material AISI P20 Mod. (\% berat) (Kusnowo, 2013)

\begin{tabular}{|c|c|c|c|c|c|c|c|c|}
\hline Komposisi & $\mathrm{C}$ & $\mathrm{Si}$ & $\mathrm{S}$ & $\mathrm{P}$ & $\mathrm{Mn}$ & $\mathrm{Ni}$ & $\mathrm{Cr}$ & $\mathrm{Mo}$ \\
\hline \% Berat & 0,44 & 0,4 & 0,01 & 0,01 & 1,5 & 0,7 & 1,9 & 0,27 \\
\hline
\end{tabular}

Setelah proses pengecoran, dilakukan proses normalizing atau menormalkan yaitu jenis proses perlakuan panas yang umum diterapkan pada hampir semua produk cor, over heated forgings dan produk produk tempa yang besar. Normalizing ditujukan untuk memperhalus butir, memperbaiki mampu mesin, menghilangkan tegangan sisa dan juga memperbaiki sifat mekanik baja karbon konstruksi dan baja baja paduan rendah (Suratman, 1998).

Pada perlakuan panas selanjutnya dilakukan proses hardening material dengan cara memanaskan pada temperatur $850^{\circ} \mathrm{C}$, kemudian di quench dalam media oli. Selanjutnya dilakukan tempering dengan 3 variasi temperatur yaitu $200^{\circ} \mathrm{C}, 400^{\circ} \mathrm{C}$, dan $600^{\circ} \mathrm{C}$.

Menurut Suratman (1998), proses perlakuan panas adalah suatu proses mengubah sifat logam dengan cara mengubah struktur mikro melalui proses pemanasan dan pengaturan kecepatan pendinginan dengan atau tanpa merubah komposisi kimia logam yang bersangkutan.

Tujuan proses perlakuan panas untuk menghasilkan sifat- sifat logam yang diinginkan. Perubahan sifat logam akibat proses perlakuan panas dapat mencakup keseluruhan bagian dari logam atau sebagian dari logam.

Prinsip perlakuan panas ini pada dasarnya sangat sederhana, yaitu logam dipanaskan dengan laju pemanasan tertentu hingga mencapai temperatur tertentu dan kemudian ditahan pada temperatur tersebut dengan waktu tertentu serta akhirnya didinginkan dengan laju pendinginan tertentu pula. Adapun prinsip proses perlakuan panas yaitu :

1. Laju pemanasan

Dimana material dipanaskan sampai temperatur austenit. Adapun syarat-syarat pemanasan yaitu :

- Pemanasan yang dilakukan tidak merubah bentuk komponen (tetap dalam keadaan solid).

- Pemanasan tidak sampai pada temperatur tinggi, karena butir akan menjadi kasar.

- Berdasarkan kandungan karbon, temperatur austenisasi dibagi atas:

- Untuk baja hipoeutektoid : $\mathrm{T}=\mathrm{A}_{3} \pm 50-100^{\circ} \mathrm{C}$

- Untuk baja hipereutektoid : $\mathrm{T}=\mathrm{A}_{\mathrm{cm}} \pm 50-100^{\circ} \mathrm{C}$

- $\mathrm{T}=\mathrm{A}_{1} \pm 50-100^{\circ} \mathrm{C}$

2. Penahanan waktu (holding time),

Dimana setelah material mencapai temperatur austenit kemudian dilakukan penahan waktu pada temperatur tertentu untuk menyeragamkan struktur mikro. 
3. Laju pendinginan,

Dimana media pendingin yang digunakan yaitu oli, air, tungku dan udara terbuka.

Secara umum Proses perlakuan panas ada dua kategori, yaitu :

1. Softening (Pelunakan) : merupakan usaha untuk menurunkan sifat mekanik agar menjadi lunak dengan cara mendinginkan material yang sudah dipanaskan didalam tungku (annealing) atau mendinginkan dalam udara terbuka (normalizing).

2. Hardening (Pengerasan) : merupakan usaha untuk meningkatkan sifat material terutama kekerasan dengan cara celup cepat (quenching) material yang sudah dipanaskan ke dalam suatu media quenching berupa air, air garam, maupun oli.

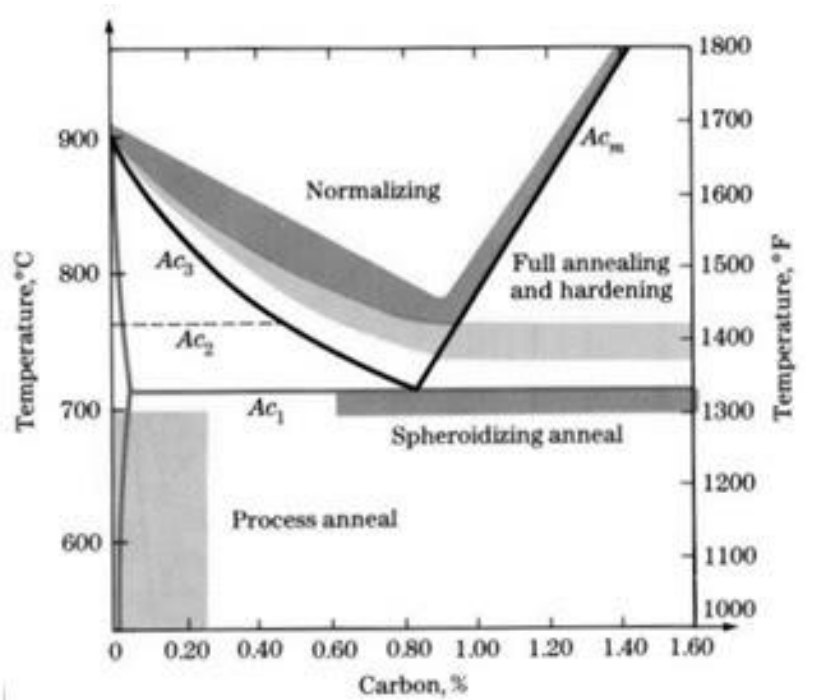

Gambar 2.1. Grafik Perlakuan panas ${ }^{[4]}$

Uji kekerasan menggunakan metoda Rockwell skala C sesuai dengan standard ASTM E18/03 (standard test methods for Rockwell Hardness, pp. 2-10) dilakukan pada lima lokasi setiap benda uji yang mendapatkan perlakuan. Tujuan pengujian dengan metode Rockwell adalah menentukan kekerasan suatu material dalam bentuk daya tahan material tersebut terhadap indentor berupa bola baja ataupun kerucut intan yang ditekankan pada permukaan material uji tersebut (Surdia dan Chijiiwa, 2000:206).

Uji tarik dilakukan sesuai dengan standar ASTM no A370, pp. 43. Tujuan uji tarik ini adalah untuk melihat kekuatan material ketika dibebani beban tarik, dalam penelitian ini menggunakan mesin Hung-Ta, dengan mengambil 2 (dua) specimen dari tiap perlakuan.

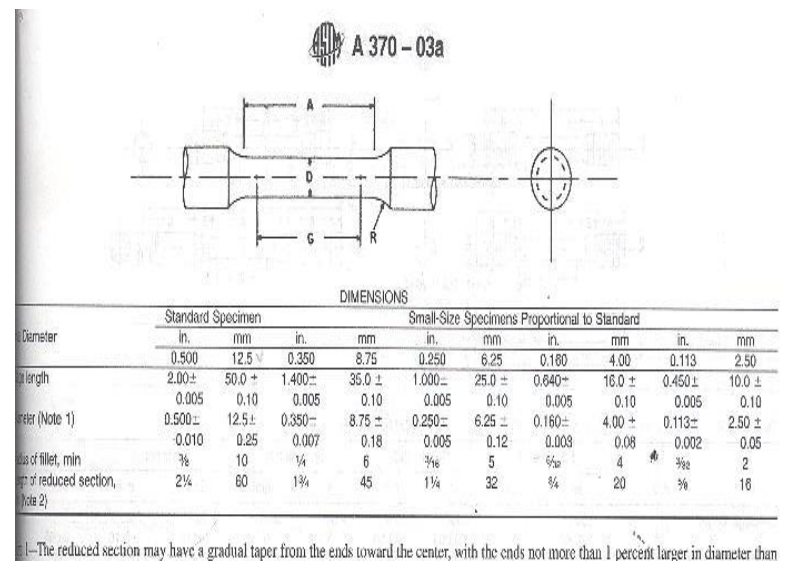

Gambar 2.2 Standar specimen uji tarik ASTM ${ }^{[2]}$

Sebelum dilakukan uji kekerasan dan uji tarik, maka untuk melihat komposisi material dilakukan uji komposisi kimia dengan spektrometer dan melakukan analisis dengan membandingkan antara hasil uji spektrometer dengan standar material AISI P20 Mod. Setelah hasilnya dinyatakan bahwa material uji sudah sesuai dengan standar baru dilakukan proses uji kekerasan dan uji tarik serta analisa hasil pengujian kekerasan dan kekuatan tarik.

\section{HASIL DAN PEMBAHASAN}

\subsection{Pengujian Komposisi Kimia}

Pengujian komposisi kimia ini menggunakan optical emission spectrometer, sampel uji diambil dari hasil pengecoran ( $Y$ blok). Berikut ini adalah data hasil uji spectrometer :

Tabel 3.1 Data hasil Spectometry (\% berat) (Kusnowo, 2013)

\begin{tabular}{|c|c|c|c|c|c|c|c|c|}
\hline Komposisi & $\mathrm{C}$ & $\mathrm{Si}$ & $\mathrm{S}$ & $\mathrm{P}$ & $\mathrm{Mn}$ & $\mathrm{Ni}$ & $\mathrm{Cr}$ & $\mathrm{Mo}$ \\
\hline \% Berat & 0,44 & 0,4 & 0,01 & 0,01 & 1,5 & 0,7 & 1,9 & 0,27 \\
\hline
\end{tabular}

\subsection{Analisa Hasil Pengujian Spektrometry}

Data hasil pengujian selanjutnya dibandingkan dengan data komposisi standar, dalam hal ini adalah AISI P20 Mod., perbandingan tersebut ditunjukkan pada tabel berikut:

Tabel 3.2 Perbandingan hasil Spectrometry dengan standar material AISI P20 Mod.

\begin{tabular}{|c|c|c|c|}
\hline Komposisi & Target & $\begin{array}{c}\text { Hasil } \\
\text { Spektrometry }\end{array}$ & Keterangan \\
\hline $\mathrm{C}$ & $0.35-0.45$ & 0,44 & ok \\
\hline $\mathrm{Si}$ & $0.2-0.4$ & 0,4 & ok \\
\hline $\mathrm{S}$ & $<0,010$ & 0,01 & ok \\
\hline $\mathrm{P}$ & $<0,010$ & 0,01 & ok \\
\hline $\mathrm{Mn}$ & $1.3-1,6$ & 1,5 & ok \\
\hline $\mathrm{Ni}$ & $0.7-1,0$ & 0,7 & ok \\
\hline $\mathrm{Cr}$ & $1.8-2.1$ & 1,9 & ok \\
\hline $\mathrm{Mo}$ & $0.15-0,3$ & 0,27 & ok \\
\hline
\end{tabular}

Data hasil pengujian menunjukkan komposisi kimia hasil pengecoran berada pada rentang yang dianjurkan oleh standar. 


\subsection{Proses Hardening dan Tempering}

Untuk memenuhi tuntutan fungsi baja, seperti keras, tahan gesekan atau beban kerja yang berat, maka baja harus dikeraskan melalui proses hardening. Prinsip dari proses hardening adalah memanaskan baja sampai titik temperatur austenit kemudian didinginkan secara mendadak / quenching dengan kecepatan pindinginan diatas kecepatan pendinginan kritis agar terjadi pembentukan martensit dan diperoleh kekerasan yang tinggi. Besarnya temperatur pemanasan austenit tergantung dari jenis baja, dan biasanya tiap-tiap produsen sudah mengeluarkan diagram suhunya masingmasing.

Menurut Suratman (1998), hardening adalah proses perlakuan panas yang diterapkan untuk menghasilkan benda kerja yang keras. Perlakuan ini terdiri dari memanaskan baja sampai ke temperatur pengerasannya (temperatur austenisasi), dan menahannya pada temperatur tersebut untuk jangka waktu tertentu dan kemudian didinginkan dengan laju pendinginan yang sangat tinggi atau di quench agar diperoleh kekerasan yang diinginkan. Jika baja di austenisasi, sel satuannya FCC. Alasan untuk memanaskan dan menahannya pada temperatur austenisasinya adalah untuk melarutkan sementit dalam austenit kemudian dilanjutkan dengan proses quench.

Pada tahap ini karbon yang terperangkap akan menyebabkan tergesernya atom atom, sehingga terbentuk struktur body center tetragonal. Atom atom yang tergeser dan karbon yang terperangkap akan menimbulkan struktur sel satuan yang tidak setimbang (memiliki tegangan tertentu). Struktur yang bertegangan ini disebut martensit dan bersifat sangat getas dan keras. Dan hal inilah yang menyebabkan tingginya kekerasan baja. Kekerasan yang dicapai tergantung pada kadar karbon yang dimiliki oleh baja tersebut. Biasanya baja yang dikeraskan diikuti dengan proses temper untuk menurunkan tegangan yang ditimbulkan akibat quenching karena adanya pembentukan martensit.

Tujuan utama proses hardening adalah untuk meningkatkan kekerasan benda kerja dan meningkatkan ketahanan aus. Makin tinggi kekerasan akan semakin tinggi pula ketahanan ausnya. Sebagai contoh spindle, roda gigi, dan dies yang memerlukan kekerasan tinggi. Setelah proses hardening biasanya baja akan sangat keras dan bersifat getas, untuk itu perlu proses lanjutan yaitu proses tempering.

Tempering merupakan proses memanaskan kembali baja yang sudah dikeraskan dengan tujuan untuk memperoleh kombinasi antara kekuatan, keuletan dan ketangguhan yang tinggi. Proses temper terdiri dari memanaskan baja sampai dengan temperatur dibawah temperatur A1, dan menahannya pada temperatur tersebut untuk jangka waktu tertentu dan kemudian didinginkan diudara (Suratman, 1998).

Tempering ini bertujuan untuk mengurangi kekerasan, mengurangi tegangan dalam, dan memperbaiki susunan struktur baja. Prinsip dari tempering adalah baja dikeraskan sampai temperatur di bawah A1(diagram $\mathrm{FeC}$ ) ditahan selama 1 jam/ $25 \mathrm{~mm}$ tebal baja, lalu didinginkan di udara dan pada suhu $300^{\circ} \mathrm{C}$ $-400^{\circ} \mathrm{C}$ dapat di quenching dengan media oli atau dapat juga didinginkan di udara.

Menurut (Suratman, 1998:77), pada saat temperatur dinaikkan, baja yang dikeraskan akan mengalami 4 tahapan sebahai berikut :

1. Pada temperatur antara $80^{\circ} \mathrm{C}$ dan $200^{\circ} \mathrm{C}$, suatu produk transisi yang kaya karbon yang dikenal sebagai karbida, berpresipitasi dari martensit tetragonal sehingga menurunkan tetragonalitas martensit. Perioda ini disebut sebagai proses temper tahap pertama. Pada saat ini, akibat keluarnya karbon, volume martensit berkontraksi. Karbida yang terbentuk pada perioda ini disebut sebagai karbida epsilon $\left(\mathrm{Fe}_{2,4} \mathrm{C}\right)$.

2. Pada temperatur antara $200^{\circ} \mathrm{C}$ dan $300^{\circ} \mathrm{C}$, austenit sisa mengurai menjadi suatu produk seperti bainit. Penampilannya mirip martensit temper. Perioda ini disebut sebagai proses temper tahap kedua.

3. Pada temperatur antara $300^{\circ} \mathrm{C}$ dan $400^{\circ} \mathrm{C}$, terjadi pembentukan dan pertumbuhan sementit dari karbida yang berpresipitasi pada tahap pertama dan kedua. Perioda ini disebut sebagai proses temper tahap ketiga. Perioda ini ditandai dengan adanya penurunan volume dan melampaui efek yang ditimbulkan dari penguraian austenit pada tahap yang kedua.

4. Pada temperatur $400^{\circ} \mathrm{C}$ dan $700^{\circ} \mathrm{C}$, pertumbuhan terus berlangsung dan disertai dengan proses sperodisasi dari sementit. Pada temperatur yang lebih tinggi lagi, terjadi pembentukan karbida kompleks $\left(\mathrm{Fe}_{\mathrm{x}} \mathrm{Cr}_{\mathrm{y}} \mathrm{Mo}_{\mathrm{z}}\right)$, pada baja yang mengandung unsur-unsur pembentuk karbida yang kuat. Perioda ini disebut sebagai proses temper tahap keempat.

Perlu diketahui bahwa rentang temperatur yang tertera pada setiap tahap proses temper, adalah spesifik. Dalam praktek, rentang temperatur tersebut bervariasi tergantung pada laju pemanasan, lama tempering, jenis dan sensitifitas pengukuran yang digunakan. Disamping itu tergantung juga pada komposisi kimia baja yang diproses. 


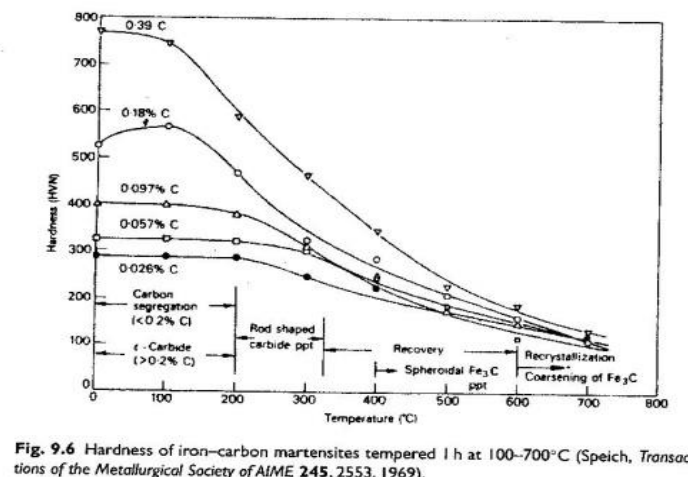

Gambar 3.1 Grafik proses tempering ${ }^{[5]}$

\subsection{Pengujian Kekerasan}

Pengujian kekerasan dilakukan pada lima lokasi disetiap benda uji yang mendapatkan perlakuan. Dari pengujian kekerasan dengan menggunakan mesin uji Rockwell skala C, diperoleh data data sebagai berikut :

Tabel 3.3 Data hasil Uji Kekerasan (Kusnowo, 2013)

\begin{tabular}{|c|c|c|c|c|c|c|c|}
\hline \multirow{2}{*}{ Perlakuan } & \multirow{2}{*}{$\begin{array}{c}\text { No } \\
\text { benda } \\
\text { uji }\end{array}$} & \multicolumn{5}{|c|}{ Nilai kekerasan pada titik (HRC) } & \multirow{2}{*}{$\begin{array}{c}\mathrm{HRC} \\
\text { rata } \\
\text { rata }\end{array}$} \\
\hline & & 1 & 2 & 3 & 4 & 5 & \\
\hline $\begin{array}{l}\text { Setelah } \\
\text { pengecoran }\end{array}$ & 1 & 39.7 & 38.8 & 39.1 & 39.5 & 38.6 & 39.1 \\
\hline Hardening & 2 & 53.6 & 53.5 & 53.5 & 54 & 54 & 53.7 \\
\hline $\begin{array}{l}\text { Tempering } \\
200^{\circ} \mathrm{C}\end{array}$ & 3 & 54 & 54.1 & 53.8 & 54 & 54 & 54 \\
\hline $\begin{array}{l}\text { Tempering } \\
400{ }^{\circ} \mathrm{C}\end{array}$ & 4 & 47.4 & 47.8 & 47.4 & 47.5 & 47.1 & 47.4 \\
\hline $\begin{array}{l}\text { Tempering } \\
600{ }^{\circ} \mathrm{C}\end{array}$ & 5 & 34.8 & 33.5 & 33.6 & 34.7 & 33.5 & 34.0 \\
\hline
\end{tabular}

\subsection{Analisa Hasil Uji Kekerasan}

Pengujian kekerasan dilakukan untuk menentukan kekerasan suatu material dalam bentuk daya tahan material tersebut terhadap indentor yang ditekankan pada permukaan material uji tersebut (Surdia dan Chijiiwa, 2000:206).

Hasil pengujian memperlihatkan nilai kekerasan dari sampel uji yang telah mengalami proses, sampel awal hasil as cast memiliki nilai kekerasan $39 \mathrm{HRC}$, nilai ini sesuai dengan struktur mikro yang terbentuknya yaitu bainit. Nilai kekerasan upper bainit sekitar 32 HRC dan lower bainit sekitar 44 HRC.

Dari proses hardening mengalami kenaikan, dari 39 HRC menjadi 53.7 HRC (571 HV). Untuk mendapatkan sifat sifat material yang baik sesuai dengan karakter yang diinginkan dapat dilakukan melalui proses perlakuan panas dan proses pendinginan. Tujuan dari proses perlakuan panas dan proses pendinginan adalah untuk mengubah struktur mikro material, sehingga sifat material tersebut berubah, seperti meningkatkan atau menurunkan sifat kekerasannya.

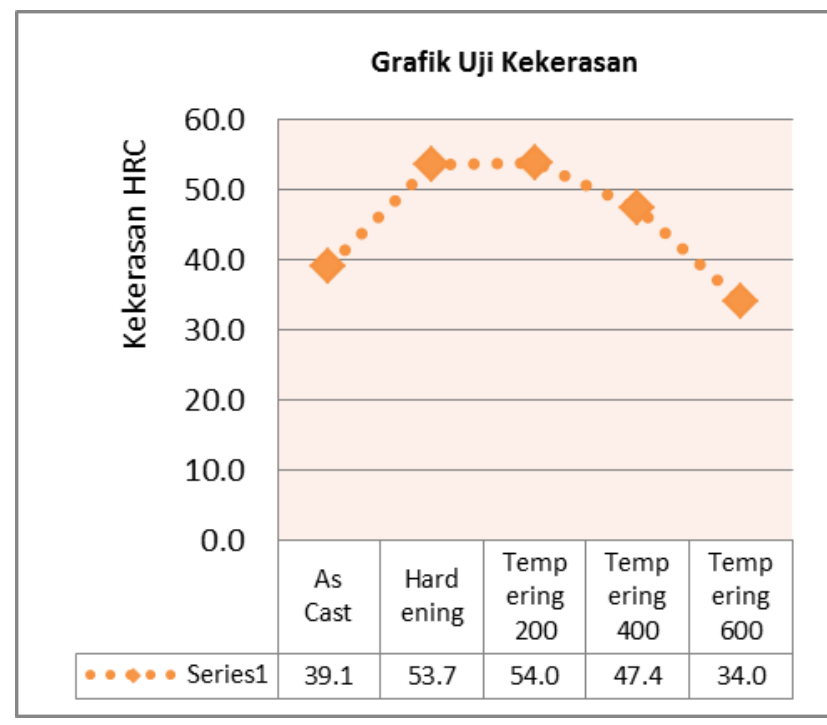

Gambar 3.2 Grafik Hasil uji Kekerasan pada beberapa perlakuan

Sesuai dengan diagram CCT (gambar 3.3) untuk AISI P20 Mod. dengan pendinginan cepat pada media oli akan menyebabkan karbon terperangkap, sehingga atom atom tergeser, dan terbentuk struktur body center tetragonal. Atom-atom yang tergeser dan karbon yang terperangkap akan menimbulkan struktur sel satuan yang tidak setimbang, struktur yang bertegangan ini disebut martensit dan bersifat sangat keras akan terbentuk martensit.

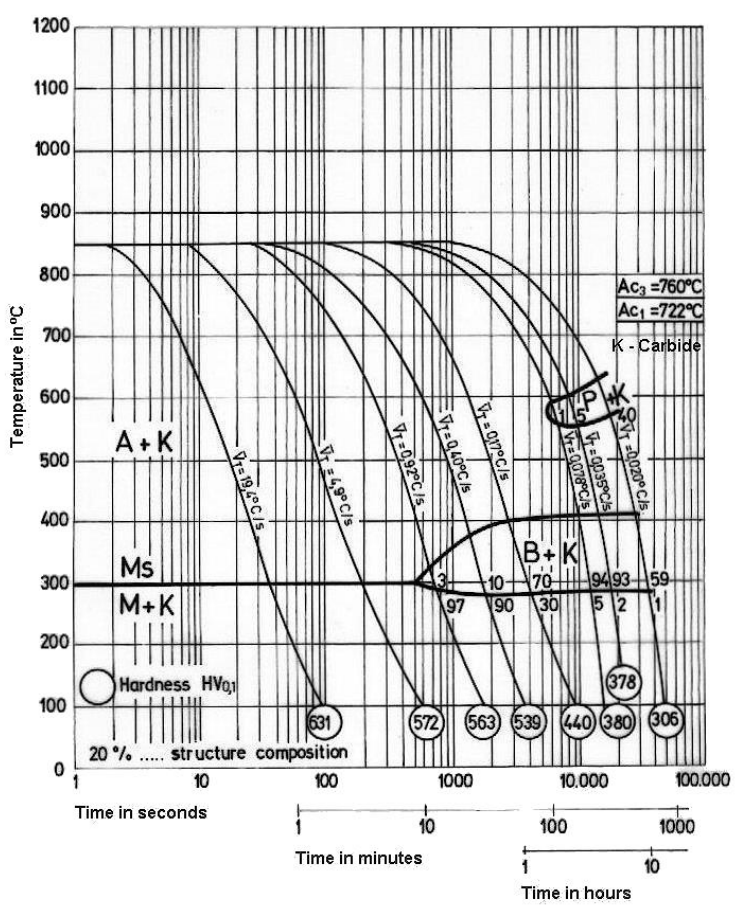

Gambar 3.3 Diagram CCT (continous cooling temperatur ${ }^{[7]}$ 


\section{Material cetakan pada aplikasi plastik}

Untuk aplikasi cetakan pembuatan produk plastik digunakan material mold tool steel (P) yang mempunyai kadar karbon $<0.4 \%$, dengan paduan $\mathrm{Cr}$, Ni, Mo dan standar kekerasan yang direkomendasikan (HRC).

Tabel 3.4 Standar kekerasan material (HRC) ${ }^{[1]}$

\begin{tabular}{|c|c|c|c|}
\hline Proses & $\begin{array}{c}\text { Material } \\
\text { yang diinjeksi }\end{array}$ & $\begin{array}{c}\text { Tipe } \\
\text { Material } \\
\text { Mold }\end{array}$ & $\begin{array}{c}\text { Kekerasan yang } \\
\text { direkomendasikan } \\
(\mathrm{HRC})\end{array}$ \\
\hline $\begin{array}{l}\text { Injection } \\
\text { Moulding }\end{array}$ & Thermoplastic & $\begin{array}{c}\text { P20 } \\
\text { P6 } \\
\text { S7 } \\
\text { H13 } \\
420 \\
\text { Elmax }\end{array}$ & $\begin{array}{l}33-35 \\
54-58 \\
54-58 \\
45-54 \\
50-54 \\
58-60\end{array}$ \\
\hline $\begin{array}{l}\text { Injection } \\
\text { Moulding }\end{array}$ & Thermoset & $\begin{array}{c}\text { S7 } \\
\text { A2 } \\
\text { D2 } \\
\text { Elmax (c) } \\
\text { ASP23 (d) }\end{array}$ & $\begin{array}{l}54-58 \\
58-60 \\
58-60 \\
58-60 \\
60-64\end{array}$ \\
\hline $\begin{array}{l}\text { Compression } \\
\text { moulding }\end{array}$ & Thermoset & $\begin{array}{c}\text { S7 } \\
420 \\
\text { Elmax (c) } \\
\text { D2 } \\
\text { ASP23 (d) }\end{array}$ & $\begin{array}{l}54-58 \\
52-54 \\
58-60 \\
58-60 \\
60-64\end{array}$ \\
\hline $\begin{array}{l}\text { Blow } \\
\text { molding }\end{array}$ & $\begin{array}{l}\text { General } \\
\text { thermoset } \\
\text { thermoplastic } \\
\text { Polyvinyl } \\
\text { choride }\end{array}$ & $\begin{array}{c}\text { P20 (a) } \\
420 \\
420 \mathrm{~F}\end{array}$ & $\begin{array}{l}33-35 \\
45-54 \\
35-37\end{array}$ \\
\hline Ekstrusion & $\begin{array}{l}\text { General } \\
\text { thermoset } \\
\text { thermoplastic } \\
\text { Polyvinyl } \\
\text { choride }\end{array}$ & $\begin{array}{c}\text { P20 (a) } \\
420 \\
420 \mathrm{~F}\end{array}$ & $\begin{array}{l}33-35 \\
45-48 \\
37-38\end{array}$ \\
\hline $\begin{array}{l}\text { Holder } \\
\text { material }\end{array}$ & $\begin{array}{l}\text { General } \\
\text { thermoset } \\
\text { thermoplastic }\end{array}$ & $\begin{array}{c}41310 / 4135 \\
420 \mathrm{~F}\end{array}$ & $\begin{array}{l}33-35 \\
37-38\end{array}$ \\
\hline
\end{tabular}

Pada proses tempering $200^{\circ} \mathrm{C}$, menunjukkan nilai kekerasan sedikit meningkat menjadi 54 HRC, peningkatan kekerasan ini dikarenakan terbentuknya karbida $\varepsilon\left(\mathrm{Fe}_{2,4} \mathrm{C}\right)$. Pada temperatur antara $80^{\circ} \mathrm{C}-200^{\circ} \mathrm{C}$, material kaya akan karbon yang dikenal dengan karbida, berpresipitasi dari martensit tetragonal sehingga menurunkan tetragonalitas dari martensit. Akibat keluarnya karbon, volume martensit berkontraksi, karbida yang terbentuk adalah karbida epsilon $\left(\mathrm{Fe}_{2,4} \mathrm{C}\right)$.

Sedangkan pada temperatur $400^{\circ} \mathrm{C}$, terjadi penurunan nilai kekerasan menjadi $47.4 \mathrm{HRC}$, hal ini disebabkan karena terjadi pembentukan dan pertumbuhan sementit dari karbida yang berpresipitasi pada tahap pertama dan kedua. Semakin tinggi temperatur tempering karbon berdifusi keluar dari rongga tetragonal.

Begitu juga pada tempering $600^{\circ} \mathrm{C}$, kekerasan sampel menurun menjadi $34.0 \mathrm{HRC}$, jika proses tempering dilakukan pada temperatur tinggi, difusi karbon akan semakin tinggi. Pertumbuhan sementit terus berlangsung dan disertai dengan proses sperodisasi dari sementit. Adapun target kekerasan yang diinginkan adalah 30-35 HRC sesuai dengan standar kekerasan material pada tabel 34, sehingga hasil kekerasan setelah dilakukan tempering $600^{\circ} \mathrm{C}$ masuk dalam target yang diinginkan.

\subsection{Data Hasil Uji Tarik}

Pengujian tarik dilakukan dengan jalan memberikan beban tarik pada material uji secara perlahan-lahan sampai patah (Surdia dan Chijiiwa, 2000:207).

Pengujian dilakukan dengan mengambil dua specimen dari tiap perlakuan dan dari pengujian tersebut didapatkan hasil kekuatan tarik. Adapun hasil dari uji tarik adalah sebagai berikut:

Tabel 3.5 Data hasil Uji Tarik (Kusnowo, 2013)

\begin{tabular}{|l|c|c|c|}
\hline \multicolumn{1}{|c|}{ Perlakuan } & \multicolumn{2}{|c|}{$\begin{array}{c}\text { Kekuatan Tarik pada } \\
\text { sampel ke }\end{array}$} & $\begin{array}{c}\text { Rata rata } \\
\text { N/mm }\end{array}$ \\
\cline { 2 - 3 } & $\mathbf{1}\left(\mathbf{N} / \mathbf{m m}^{\mathbf{2}}\right)$ & $\mathbf{2}\left(\mathbf{N} / \mathbf{m m}^{\mathbf{2}}\right)$ & \\
\hline Setelah pengecoran & 685 & 625 & $\mathbf{6 5 5}$ \\
\hline Hardening & 1117.1 & 1370.9 & $\mathbf{1 2 4 4}$ \\
\hline Tempering $200{ }^{\circ} \mathrm{C}$ & 1537.9 & 1493.8 & $\mathbf{1 5 1 5 . 8}$ \\
\hline Tempering $400{ }^{\circ} \mathrm{C}$ & 1226.3 & 1569.5 & $\mathbf{1 3 9 7 . 9}$ \\
\hline Tempering $600^{\circ} \mathrm{C}$ & 1094.0 & 1061.4 & $\mathbf{1 0 7 7 . 7}$ \\
\hline
\end{tabular}

\subsection{Analisa Hasil Uji Tarik}

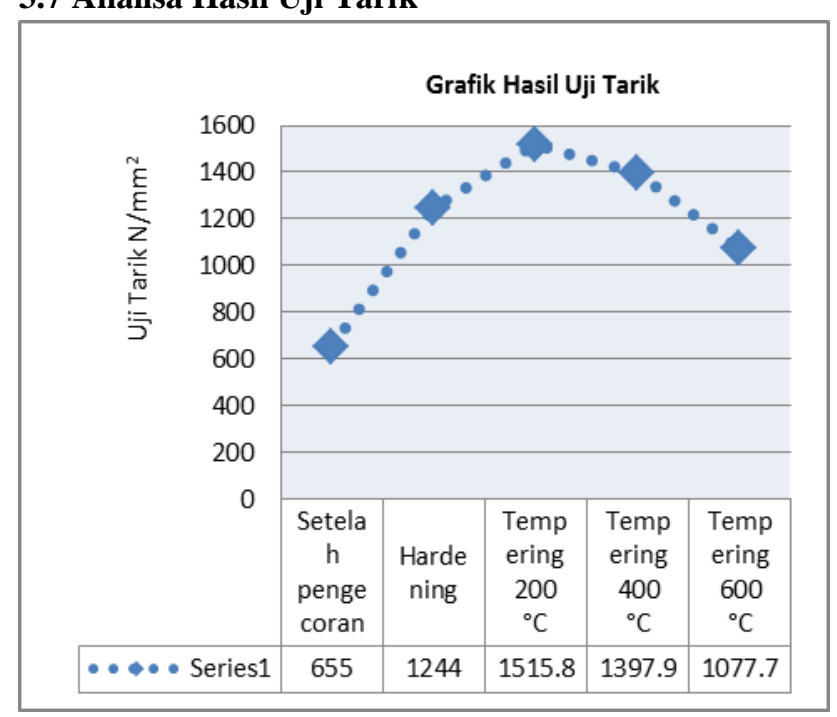

Gambar 3.4 Grafik Hasil Uji Tarik 
Dilihat dari grafik 3.4 nilai dari kekuatan tarik dari kondisi as cast benda sampai dilakukan proses hardening dan tempering pada tiga variasi temperatur.

Pada kondisi awal benda, hasil uji tarik adalah 655 $\mathrm{N} / \mathrm{mm} 2$, artinya kekuatan tarik material yang dihasilkan masih jauh dari target kekuatan tarik, setelah melalui proses hardening rata-rata kekuatan tarik meningkat menjadi $1244 \mathrm{~N} / \mathrm{mm}^{2}$.

Proses tempering suhu $200^{\circ} \mathrm{C}$ dihasilkan uji tarik dengan kekuatan tarik meningkat lagi menjadi 1515.8 $\mathrm{N} / \mathrm{mm}^{2}$. Hal ini dikarenakan terbentuknya karbida $\varepsilon$.

Pada proses tempering suhu $400^{\circ} \mathrm{C}$, terjadi penurunan nilai kekuatan material menjadi 1397.9 $\mathrm{N} / \mathrm{mm}^{2}$, hal ini dikarenakan terbentuknya martensit temper, dimana sifatnya lebih lunak dari martensit, sehingga nilai kekuatannya turun.

Selanjutnya pada proses tempering suhu $600^{\circ} \mathrm{C}$, nilai kekuatan tarik menjadi $1077.7 \mathrm{~N} / \mathrm{mm}^{2}$ dengan elongasi $11 \%$ mendekati target kekuatan tarik yaitu 1020 $\mathrm{N} / \mathrm{mm}^{2}$ dan target elongasi $11 \%$ s.d. $12 \%$. Hal ini disebabkan kenaikan temperatur pada proses tempering berakibat atom-atom berdifusi membentuk fasa stabil, dalam hal ini ferrit dan sementit.

\section{PENUTUP}

\section{Kesimpulan}

Sesuai dengan tujuan penelitian yaitu untuk menganalisis uji kekerasan dan uji tarik pada material AISI P20 Mod. hasil proses hardening dan tempering pada suhu yang berbeda-beda, maka berdasarkan hasil dan pembahasan dapat disimpulkan sebagai berikut :

1. Uji kekerasan pada proses hardening mencapai nilai kekerasan 53,7 HRC.

2. Uji kekerasan dari proses tempering suhu $200^{\circ} \mathrm{C}$ menunjukkan nilai kekerasan sedikit meningkat menjadi 54 HRC

3. Uji kekerasan pada temperatur $400^{\circ} \mathrm{C}$ terjadi penurunan nilai kekerasan menjadi 47,4 HRC.

4. Uji kekerasan pada proses tempering pada suhu $600^{\circ} \mathrm{C}$ masuk target kekerasan yang diinginkan yaitu pada $34 \mathrm{HRC}$.

5. Uji tarik pada proses hardening menghasilkan kekuatan tarik sebesar1244 N/mm².

6. Uji tarik pada proses tempering pada suhu $200^{\circ} \mathrm{C}$ menunjukkan kekuatan tarik $1515.8 \mathrm{~N} / \mathrm{mm}^{2}$.

7. Uji tarik pada temperatur $400^{\circ} \mathrm{C}$ menghasilkan kekuatan tarik $1397.9 \mathrm{~N} / \mathrm{mm}^{2}$.

8. Uji tarik dari proses tempering pada suhu $600^{\circ} \mathrm{C}$ menunjukkan hasil kekuatan tarik sebesar 1077.7 $\mathrm{N} / \mathrm{mm}^{2}$ mendekati nilai target kekuatan tarik.

9. Berdasarkan uji kekerasan dan uji tarik dapat dinyatakan bahwa material uji dalam penelitian ini sesuai dengan standar material AISI P20 Mod. dan layak untuk dipergunakan.

\section{Saran}

Peneliti menyarankan untuk menunjang dan melengkapi hasil penelitian saat ini perlu dilakukan pula penelitian lanjutan berupa analisis ketangguhan material AISI P20 Mod. dengan uji impak yang bertujuan untuk melihat ketahanan material terhadap pembebanan yang bersifat tiba-tiba, dan melihat material getas atau ulet. Sedangkan untuk melihat secara lengkap sifat-sifat mekanik pada material penelitian dapat dilakukan melalui analisis uji metalography yang bertujuan untuk melihat hasil struktur mikro yang terjadi.

\section{DAFTAR PUSTAKA}

[1] ASM Handbook, Tool Steels, $5^{\text {th }}$ edition, ASM International, USA, 1998.

[2] ASTM no A370, pp. 43. Available https://law.resource.org/pub/us/cfr/ibr/003/astm. a370.1977.pdf diakses 14 September 2015.

[3] ASTM E18/03 (standard test methods for Rockwell Hardnes), pp. 2-10. Available http://www.udistrital.edu.co:8080/documents/19 625/ae6ee1b6-9b5b-4452-afcd-ddb1e9e045c5 diakses 14 September 2015.

[4] Callister Jr., W.D., Material Science and Engineering An Introduction. Seventh Edition. New York: John Wiley \& Sons, Inc., 2007.

[5] Krauss, G., Steels: Heat Treatment and Processing Principles. ASM International, 1990.

[6] Kusnowo, R., "Pengaruh Temperatur Tempering terhadap Sifat Mekanik Baja Cor DIN 1.2738", M.S. thesis. Fakultas Teknik Mesin dan Dirgantara, Institut Teknologi Bandung, Indonesia, 2013.

[7] Steel UTOPNIN (Mat.No. 1.2738, DIN 40CrMnNiMo8-6-4, AISI P20 Mod..). CCT Diagram.Available http:// www. metalravne. com/steelselector/steels/UTOPNIN.html diakses 14 September 2015.

[8] Suratman, R., Panduan Proses Perlakuan Panas, Bandung: Lembaga Penelitian Institut Teknologi Bandung, 1998.

[9] Surdia, T., dan Chiijiwa, K. Teknik Pengecoran Logam. Jakarta: PT Pradnya Paramita. 2000. 